\title{
Characterization of immune response to neurofilament light in experimental autoimmune encephalomyelitis
}

Fabiola Puentes ${ }^{1 *+}$, Baukje J van der Star ${ }^{2+}$, Marion Victor $^{3}$, Markus Kipp ${ }^{3}$, Cordian Beyer $^{3}$, Regina Peferoen-Baert ${ }^{2}$, Kimberley Ummenthum², Gareth Pryce ${ }^{1}$, Wouter Gerritsen², Ruth Huizinga ${ }^{4}$, Arie Reijerkerk ${ }^{5}$, Paul van der Valk², David Baker ${ }^{1}$ and Sandra Amor ${ }^{1,2}$

\begin{abstract}
Background: Autoimmunity to neuronal proteins occurs in several neurological syndromes, where cellular and humoral responses are directed to surface as well as intracellular antigens. Similar to myelin autoimmunity, pathogenic immune response to neuroaxonal components such as neurofilaments may contribute to neurodegeneration in multiple sclerosis.
\end{abstract}

Methods: We studied the immune response to the axonal protein neurofilament light (NF-L) in the experimental autoimmune encephalomyelitis animal model of multiple sclerosis. To examine the association between $T$ cells and axonal damage, pathology studies were performed on NF-L immunized mice. The interaction of $T$ cells and axons was analyzed by confocal microscopy of central nervous system tissues and T-cell and antibody responses to immunodominant epitopes identified in $\mathrm{ABH}\left(\mathrm{H} 2-\mathrm{A}^{97}\right)$ and $\mathrm{SJ} / \mathrm{J}\left(\mathrm{H} 2-\mathrm{A}^{\mathrm{s}}\right)$ mice. These epitopes, algorithm-predicted peptides and encephalitogenic motifs within NF-L were screened for encephalitogenicity.

Results: Confocal microscopy revealed both $\mathrm{CD}^{+}$and $\mathrm{CD}^{+} \mathrm{T}$ cells alongside damaged axons in the lesions of NF-L immunized mice. CD4 ${ }^{+} T$ cells dominated the areas of axonal injury in the dorsal column of spastic mice in which the expression of granzyme B and perforin was detected. Identified NF-L epitopes induced mild neurological signs similar to the observed with the NF-L protein, yet distinct from those characteristic of neurological disease induced with myelin oligodendrocyte glycoprotein.

Conclusions: Our data suggest that $\mathrm{CD}^{+} \mathrm{T}$ cells are associated with spasticity, axonal damage and neurodegeneration in NF-L immunized mice. In addition, defined T-cell epitopes in the NF- $L$ protein might be involved in the pathogenesis of the disease.

Keywords: Neurofilament light, Axonal damage, Neurodegeneration, Experimental autoimmune encephalomyelitis, Multiple sclerosis

\section{Introduction}

Multiple sclerosis (MS) is a chronic demyelinating and neurodegenerative disease of the central nervous system (CNS) widely considered due to aggressive, autoreactive $\mathrm{T}$ cells and antibodies to myelin [1-3]. However, accumulating evidence shows that immune responses to neuronal

\footnotetext{
*Correspondence: f.puentes@qmul.ac.uk

${ }^{\dagger}$ Equal contributors

${ }^{1}$ Neuroimmunology Unit, Blizard Institute, Bart's and the London School of Medicine and Dentistry, Queen Mary University of London, London E1 2AT, UK Full list of author information is available at the end of the article
}

and axonal proteins are also present in a wide range of neurodegenerative disorders including MS [4-6]. That these responses may contribute to axonal and neuronal damage, pathological hallmarks of MS, is supported by observations that immunization with neuronal antigens and transfer of antibodies directed to neuronal and axonal proteins induce neuronal damage in animals [7-10].

The lack of expression of molecules of the major histocompatibility complex (MHC) class II on neurons indicates 
that neurons cannot activate $\mathrm{CD} 4^{+}$cells in an antigenspecific manner. However, neurons constitutively express or readily upregulate expression of MHC class I during inflammation, indicating that neurons may become targets for $\mathrm{CD}^{+} \mathrm{T}$ cells [11]. Conceptually, both $\mathrm{CD} 4^{+}$ and $\mathrm{CD}^{+} \mathrm{T}$ cells could mediate attack on axons and neurons, either by direct contact via antigen-independent interactions or as a result of collateral damage [12]. Activated $\mathrm{T}$ cells in the CNS are reported to produce cytotoxic molecules as well as glutamate, nitric oxide and reactive oxygen species that could contribute to the damage and progressive neurodegeneration observed in MS and other neurodegenerative diseases in which inflammation has been described [13-15]. In addition, activation of $\mathrm{B}$ cells might lead to the production of specific antibodies to neuronal antigens that could also contribute to the damage and progressive neurodegeneration [16].

To examine the mechanisms of autoimmunity to neurons we have developed a model of autoimmune induced axonal and neuronal damage following immunization of mice with the neuronal cytoskeletal protein neurofilament light (NF-L) [7]. Whether T-cell responses to neuroaxonal components are pathogenic in MS is as yet unknown; although we have recently shown that NF-L is phagocytosed by MHC class $\mathrm{II}^{+}$microglia/macrophages in MS brain lesions [17], indicating a potential source by which autoreactive T cells could become reactivated in MS. In mice, we have shown that autoimmunity to NF-L causes spasticity and neurodegeneration and that axonal damage is a direct consequence of such responses $[7,8]$. Infiltration of $\mathrm{CD}^{+} \mathrm{T}$ cells and $\mathrm{B} 220^{+}$cells mainly localized in the dorsal column of the spinal cord of NF-L immunized mice was also observed [8]. Likewise, immunoglobulin deposits were observed into the axons in mice immunized with NF-L protein [7].

In the present study, we characterized the T-cell infiltrates in the CNS of spastic mice. Both $\mathrm{CD} 4^{+}$and $\mathrm{CD} 8^{+}$ $\mathrm{T}$ cells were found in close association to axons, although $\mathrm{CD} 4^{+} \mathrm{T}$ cells dominated the infiltrates in lesions. In addition, increased perforin expression and cells positive for granzyme B could be observed in the spinal cord of mice immunized with NF-L. Furthermore, NF-L peptides were screened for $\mathrm{T}$-cell and $\mathrm{B}$-cell responses in $\mathrm{ABH}\left(\mathrm{H} 2-\mathrm{A}^{\mathrm{g} 7}\right)$ and SJL/J $\left(\mathrm{H} 2-\mathrm{A}^{\mathrm{s}}\right)$ mice, and the pathogenic potential of these peptides and predicted binding motifs to $\mathrm{H} 2-\mathrm{A}^{\mathrm{g} 7}$ present in the NF-L sequence were investigated.

In summary, our study reveals that $\mathrm{T}$ cells associated with the expression of cytotoxic molecules are present in lesions in the dorsal columns of spastic mice immunized with NF-L and we show, for the first time, that active immunization with defined NF-L peptides induced neurological disease in $\mathrm{ABH}$ mice.

\section{Materials and methods}

Mice

Male and female 10-week-old Biozzi ABH $\left(\mathrm{H}-2^{\mathrm{dq} 1}\right)$ and $\mathrm{SJL} / \mathrm{J}\left(\mathrm{H}-2^{\mathrm{S}}\right)$ mice were obtained from Harlan (Bicester, UK) and Charles River laboratories (Kent, UK) or were bred at QMUL (London, UK). All procedures were performed in accordance with the UK Animals (Scientific Procedures) Act (1986) and approved by the local ethics committee. All procedures were performed following Institutional ethical review in accordance to the United Kingdom Animals (Scientific Procedures) Act (1986) and European Union Directive 2010/63/EU. Animals were housed and monitored consistent with the principles of the ARRIVE guidelines as described previously [18].

\section{Antigens}

Spinal cord homogenate (SCH) prepared from $60 \mathrm{ABH}$ mice was lyophilized and reconstituted in PBS as described previously [18]. rmNF-L was prepared as described previously [17]. Overlapping 16-amino-acid peptides (Table 1) based on the mouse protein sequence (NCBI protein ID: NP035040) and myelin oligodendrocyte glycoprotein $\left(\mathrm{MOG}^{35-55}\right)$ peptide (MEVGWYRSPFSRVVHLYRNGK) were synthesized as peptide amides $\left(\mathrm{CONH}_{2}\right)$ (Cambridge Research Biochemicals Ltd, Billingham, UK).

Induction of experimental autoimmune encephalomyelitis Mice were injected subcutaneously with $1 \mathrm{mg} \mathrm{SCH}$, $200 \mu \mathrm{g}$ rmNF-L, $200 \mu \mathrm{g} \mathrm{MOG}^{35-55}$ or rmNF-L and MOG $^{35-55}(1: 1)$, or pools of $30 \mu$ g each peptide emulsified with incomplete Freund's adjuvant (Difco Laboratories, (Detroit, Michigan, USA) UK) supplemented with $48 \mu \mathrm{g}$ Mycobacterium tuberculosis and $6 \mu \mathrm{g}$ Mycobacterium butyricum (Difco Laboratories) on day 0 and day 7 as described previously [19]. Control mice were immunized with complete Freund's adjuvant (CFA) only. All mice were injected with $200 \mathrm{ng}$ Bordetella pertussis toxin (Sigma St. Louis, Missouri, USA) intraperitoneally, immediately after immunization and 24 hours later.

To identify encephalitogenic epitopes, four to six mice were immunized with rmNF-L, individual or pooled peptides. To optimize identification, sequences containing motifs that bind to or interact with $\mathrm{H} 2-\mathrm{A}^{\mathrm{g} 7}$ were selected as described previously [19]. The Rankpep server was additionally used to predict binding to $\mathrm{H} 2-\mathrm{A}^{\mathrm{g} 7}$ [20].

Mice were monitored daily and scored according to a neurological scale: 0 , normal; 0.5 , partial loss of tail tone; 1 , paralysis or spasticity of the tail; 2, impaired righting reflex; 3, paralysis or spastic paresis of one limb; 4, paralysis or spastic paresis of two limbs; and 5, moribund $[7,18]$. Mice were sacrificed by carbon dioxide inhalation and brains and spinal cords snap-frozen in liquid nitrogen or processed for pathology [7]. 
Table 1 Sequences of mouse neurofilament-light peptides ${ }^{a}$

\begin{tabular}{|c|c|c|c|}
\hline equence & Amino acid & Sequence & Amino acid \\
\hline to 16 & SSFGYDPYFSTSYKRR & 273 to 288 & MQNAEEWFKSRFTVLT \\
\hline to 24 & FSTSYKRRYVETPRVH & 281 to 296 & KSRFTVLTESAAKNTD \\
\hline 2 & Y & 4 & AKDE \\
\hline to 40 & RSAYS & 297 to 312 & AVRAAKD \\
\hline to 48 & APVSS & 305 to 320 & VSESRRL \\
\hline to 56 & VRRSY & to 328 & RGMNEA \\
\hline to 64 & SGSLM & 336 & QLQEL \\
\hline 12 & ENLDL & 329 & NADI \\
\hline to 80 & PSLENLDLSQVAAISN & 337 to 352 & EDKQNADISAMQDTIN \\
\hline 80 & SQV & 345 & sal \\
\hline 1 to 96 & DLKSIRTQEKAQLQDL & 353 to 368 & KLENELRSTKSEMARY \\
\hline to 104 & EKAQLQDLNDRFASFI & 361 to 376 & TKSEMA \\
\hline to 112 & NDRFASFIERVHELEQ & 369 to 384 & LKEYQL \\
\hline 5 to 120 & ERVHELEQQNKVLEAE & 377 to 392 & NVKMALDIEIAAYRKL \\
\hline 128 & QNK & 38 & $E$ \\
\hline 121 to 136 & LLVLRQKHSEPSRFRA & 393 to 408 & LEGEETRLSFTSVGSI \\
\hline 4 & S & 4 & S \\
\hline 137 to 152 & LYEQEIRDLRLAAEDA & 409 to 424 & TSGYSQSSQVFGRSAY \\
\hline 145 to 160 & LRLAAEDATNEKQALQ & 417 to 432 & QVFGRSAYSGLQSSSY \\
\hline 153 to 168 & TNEKQALQGEREGLEE & 440 & SARSFP \\
\hline 161 to 176 & GEREGLEETLRNLQAR & 433 to 448 & LMSARSFPAYYTSHVQ \\
\hline 16 & TLF & 4 & $E$ \\
\hline 177 to 192 & YEEEVLSREDAEGRLM & 449 to 464 & EEQTEVEETIEATKAE \\
\hline 185 to 200 & EDAEGRLMEARKGADE & 457 to 472 & TIEATKAEEAKDEPPS \\
\hline 193 to 208 & EARKGADEAALARAEL & 465 to 480 & EAKDEPPSEGEAEEEE \\
\hline 201 to 216 & AALARAELEKRIDSLM & 473 to 488 & EGEAEEEEKEKEEGEE \\
\hline 4 & $\mathrm{E}$ & 4 & K \\
\hline 217 to 232 & DEIAFLKKVHEEEIAE & 489 to 504 & EEGAEEEEAKDESEDT \\
\hline ○ 240 & VHEEEIAELQAQIQYA & 497 & AKDESEDTKEEEEGGE \\
\hline 233 to 248 & LQAQIQYAQISVEMDV & 505 to 520 & GEGEEEDTKE \\
\hline 241 to 256 & QISVEMDVSSKPDLSA & 513 to 528 & GEEEDTKESEEEEKKE \\
\hline 264 & SSKPDLSAALKDIRAQ & 536 & SAGEEQV \\
\hline 257 to 272 & ALKDIRAQYEKLAAKN & 529 to 544 & ESAGEEQVAKKKD \\
\hline 65 to 280 & YEKLAAKNMQNAEEWF & & \\
\hline
\end{tabular}

${ }^{\mathrm{a}}$ Mouse neurofilament-light sequence (NCBI reference sequence: NP035040).

\section{Immunohistochemistry}

Sections $(3 \mu \mathrm{m})$ from snap-frozen spinal cord tissues were fixed with acetone and incubated overnight at $4^{\circ} \mathrm{C}$ with mAb directed to CD4 (YTS 191.1.2), CD8 (YTS 169AG; ImmunoTools, Friesoythe, Germany), MHC-I antigens (HM1091; Hycult Biotech, Plymouth Meeting, PA, USA) or biotinylated MHC-II (OX 6, a kind gift of Jack van Horssen, VU University Medical Center) diluted in antibody diluent (Immunologic; Duiven, The Netherlands). After washing, endogenous peroxidase was blocked with
$0.3 \% \mathrm{H}_{2} \mathrm{O}_{2}$ in PBS. Sections stained for CD4, CD8 and MHC-I were incubated with biotinylated rabbit antirat Ig (Dako, Glostrup, Denmark) for 1 hour, followed by peroxidase-coupled avidin-biotin complex (ABC kit; Vector Laboratories, Burlingame, CA, USA). Sections stained with biotinylated MHC-II were incubated with streptavidin-horseradish peroxidase complex (Dako) for 1 hour. All secondary antibodies were visualized with 3,3'-diaminobenzidine. Antibodies were prescreened on brain, liver, lung, spleen and tonsil tissues and isotype control mAb served as negative control. The percentage of $\mathrm{CD}^{+}$and $\mathrm{CD}^{+} \mathrm{T}$ cells were counted at $25 \times$ objective at three levels of the spinal cord.

For immunofluorescence, sections were incubated with blocking solution (CleanVision IHC/ICC; Immunologic) containing 10\% normal goat serum for 2 hours, washed in PBS and incubated with mAb to NF-L (10H9), SMI-32 (Covance, Princeton, NJ, USA) or NeuN (Merck Millipore; Darmstadt, Germany) and CD3 (CD3-12; Serotec, Oxford, UK), CD4 (YTS 191.1.2) or CD8 (YTS 169AG; ImmunoTools) overnight at $4^{\circ} \mathrm{C}$. After washing in PBS, sections were incubated with goat anti-mouse IgG1 Alexa 594 or goat anti-rat IgG Alexa 488 (Invitrogen; Paisley, UK) for 60 minutes at room temperature. Sections were viewed using confocal laser scanning microscopy (Leica DMI6000; Rijswijk, The Netherlands). Image processing was performed using NIH Image J software [21].

Granzyme B staining was performed on paraffinembedded sections $(4 \mu \mathrm{m})$. In brief, sections were deparaffinized and rinsed in $\mathrm{H}_{2} \mathrm{O}$. Subsequently, endogenous peroxidase was blocked as described above. After rinsing in PBS, antigen retrieval in Tris-ethylenediamine tetraacetic acid buffer ( $\mathrm{pH} 9.0)$ was performed in a microwave followed by incubation with $10 \%$ normal goat serum. Sections were incubated overnight at $4{ }^{\circ} \mathrm{C}$ with polyclonal rabbit anti-granzyme B (ab4059; Abcam; Cambridge, UK) in $1 \%$ BSA. Subsequently, sections were washed in PBS and incubated with secondary antibody Envision anti Rabbit labeled with horseradish peroxidase (K4002; Dako) for 30 minutes and visualized with 3,3'-diaminobenzidine.

\section{Reverse transcriptase polymerase chain reaction}

Spinal cords from control and NF-L immunized $\mathrm{ABH}$ mice were dissolved in lysis buffer (NucleoSpin RNA/ Protein kit; Machery-Nagel GmbH, Düren, Germany) and homogenized with $1.4 \mathrm{~mm}$ ceramic beads (Precellys 24; Peqlab Biotechnologie GmbH, Erlangen, Germany) at $5000 \mathrm{rpm}$ for 15 seconds. Subsequently, RNA was isolated using NuceloSpin (Macherey-Nagel) according to the manufacturer's recommendations. Purity was confirmed using 260:280 OD ratios (Nano-Drop 1000; Peqlab Biotechnologie $\mathrm{GmbH}$ ). RT reactions were performed with the MMLV RT-kit and random hexanucleotide 
primers (Invitrogen) and gene expression was measured using Taq-Polymerase (Biomol GmbH, Hamburg, Germany).

Primers for perforin amplification (sense, $5^{\prime}$-CTGCCA CTCGGTCAGAATG-3'; antisense, 5' -CGGAGGGTAG TCACATCCAT-3') were used at annealing temperature of $59^{\circ} \mathrm{C}$, amplifying an 88-base-pair fragment. Expression levels of the reference gene hypoxanthine guanine phosphoribosyl transferase were used as control. Primers for hypoxanthine guanine phosphoribosyl transferase amplification (sense, 5'-GCTGGTGAAAAGGACCTCT-3'; antisense: 5' -CACAGGACTAGAACACCTGC-3') were used at an annealing temperature of $60^{\circ} \mathrm{C}$, amplifying a 248-base-pair fragment, and primers for 18sRNA amplification (sense, 5'-CGGCTACCACATCCAAGGAA-3'; antisense, 5' -GCTGGAATTACCGCGGCT-3') were used at an annealing temperature of $60^{\circ} \mathrm{C}$, amplifying a 187base-pair fragment. Gene expression was performed using RT-PCR technology (Bio-Rad; Munich, Germany) with SYBR green (SensiMix ${ }^{\mathrm{xw}}$; Bioline; Luckenwalde, Germany), as published previously [22].

\section{T-cell proliferation assays}

$\mathrm{ABH}$ and SJL/J mice were immunized with rmNF-L in CFA or CFA only ( $n=4$ per group). Spleen cells were collected 10 days after priming and single-cell suspensions $\left(3 \times 10^{5} / \mathrm{ml}\right)$ cultured in RPMI medium (Gibco, Invitrogen; Paisley, UK) with 5\% FCS (Gibco, Invitrogen), $2 \mathrm{mM}$ L-glutamine, $100 \mathrm{U} / \mathrm{ml}$ penicillin, $100 \mu \mathrm{g} / \mathrm{ml}$ streptomycin, $5 \mathrm{mM}$ Hepes, and $5 \times 10^{-5} \mathrm{M}$ 2-mercaptoethanol (Gibco, Invitrogen). Cells were incubated with NF-L peptides or rmNF-L for 72 hours. Proliferation was determined by incorporation of $\left[{ }^{3} \mathrm{H}\right]$-thymidine (GE Healthcare, Uppsala, Sweden). Stimulation indices (SIs) were calculated as the proliferative response in the presence of antigen divided by the response in the absence of antigen. SI in the CFA control group ranged from 0.6 to 1.1. Positive stimulation was defined as SI $>1.5$.

\section{Enzyme-linked immunosorbent assay}

To identify B-cell epitopes in NF-L, Biozzi ABH and SJL/J mice ( $n=4$ per group) were immunized with rmNF-L protein in complete adjuvant and serum was collected on day 15 post immunization. The mouse immune sera were tested for their reactivity to NF-L overlapping peptides. Nunclon plates (Nunc, Roskilde, Denmark) were coated overnight at $4^{\circ} \mathrm{C}$ with $10 \mu \mathrm{g} / \mathrm{ml}$ mouse NF-L peptides or rmNF-L protein, in carbonate buffer. Plates were washed twice in PBS and blocked for 1 hour at $37^{\circ} \mathrm{C}$ with $2 \%$ BSA/PBS. After blocking, $\mathrm{ABH}$ or SJL/J immune sera, diluted 1:100 in 1\% (BSA/PBS), were added and incubated for 1 hour at room temperature. After washing in PBS-Tween $0.1 \%$, the plates were incubated for 1 hour at room temperature with horseradish peroxidase-conjugated rabbit anti-mouse Ig (Dako). The reaction product was developed with TMB substrate (Thermo Fisher Scientific; Loughborough, UK) and stopped by the addition of $2 \mathrm{M}$ hydrochloric acid. The absorbance was measured at $450 \mathrm{~nm}$, using a Synergy HT microplate reader (Bio-Tek instruments; Winooski, Vermont, USA). Background values were obtained by the reactivity of immune serum on peptide uncoated wells. An absorbance above the mean plus three standard deviations of the background reactivity was taken as positive.

\section{Statistical analysis}

For comparison of clinical experimental autoimmune encephalomyelitis (EAE) scores, significance between the groups was determined by nonparametric Mann-Whitney rank-sum test (SigmaStat; Systat Software Inc., San Jose, CA, USA). Data represent the mean \pm standard error of the mean $\left({ }^{* *} P<0.01,{ }^{*} P<0.05\right)$.

\section{Results \\ $\mathrm{CD} 4^{+}$and $\mathrm{CD} 8^{+} \mathrm{T}$ cells are associated with neuronal/axonal damage in spastic mice}

To examine the presence of $\mathrm{T}$ cells in the CNS during disease, $\mathrm{CD}^{+}$or $\mathrm{CD}^{+} \mathrm{T}$ cells within the lesions of NF-L immunized mice at the peak of disease were examined. Using immunohistochemistry, the ratio of $\mathrm{CD}^{+}$and $\mathrm{CD} 8^{+}$ $\mathrm{T}$ cells in the lesions was determined (Figure 1A, B, respectively). We observed that significantly more $\mathrm{CD}^{+} \mathrm{T}$ cells were present within the lesions in a ratio of $9: 1 \mathrm{CD} 4^{+}: \mathrm{CD} 8^{+}$ $\mathrm{T}$ cells (data not shown). To support a role for $\mathrm{CD} 8^{+} \mathrm{T}$ cells we examined the expression of MHC class I in the spinal cord of diseased mice. In contrast to expression of MHC class I antigens on inflammatory cells in the lesion as well as perivascular cells (Figure 1C) and microglia in normalappearing white matter (Figure 1D), there was no evidence of MHC-class I antigen expression on neurons or axons in the lesions (Figure 1E, F) or in normal-appearing tissues (data not shown). Likewise, while MHC class II was expressed on inflammatory cells in the blood vessels and in the parenchyma, being present on ramified cells resembling microglia (Figure 1G), no expression on neurons and axons was observed (Figure 1H, I), as has been shown before in normal or pathological tissues during EAE [23].

To examine the interaction of $\mathrm{T}$ cells and axons we used confocal microscopy of CNS tissues from spastic mice. We observed a close association of $\mathrm{CD}^{+} \mathrm{T}$ cells aligning with possible damaged axons as indicated by SMI-32 staining (Figure 2A), in which there was close association between the $\mathrm{T}$ cell and the axon (Figure 2A, insert). In cross-sections of the lesion, $\mathrm{CD} 4^{+} \mathrm{T}$ cells were observed within areas of axonal damage (Figure 2B) and frequently observed between axons with increased immunoreactivity for SMI-32 and neurofilament, indicating axonal damage (Figure $2 \mathrm{C}, \mathrm{D}$ ). While $\mathrm{CD}^{+} \mathrm{T}$ cells were 


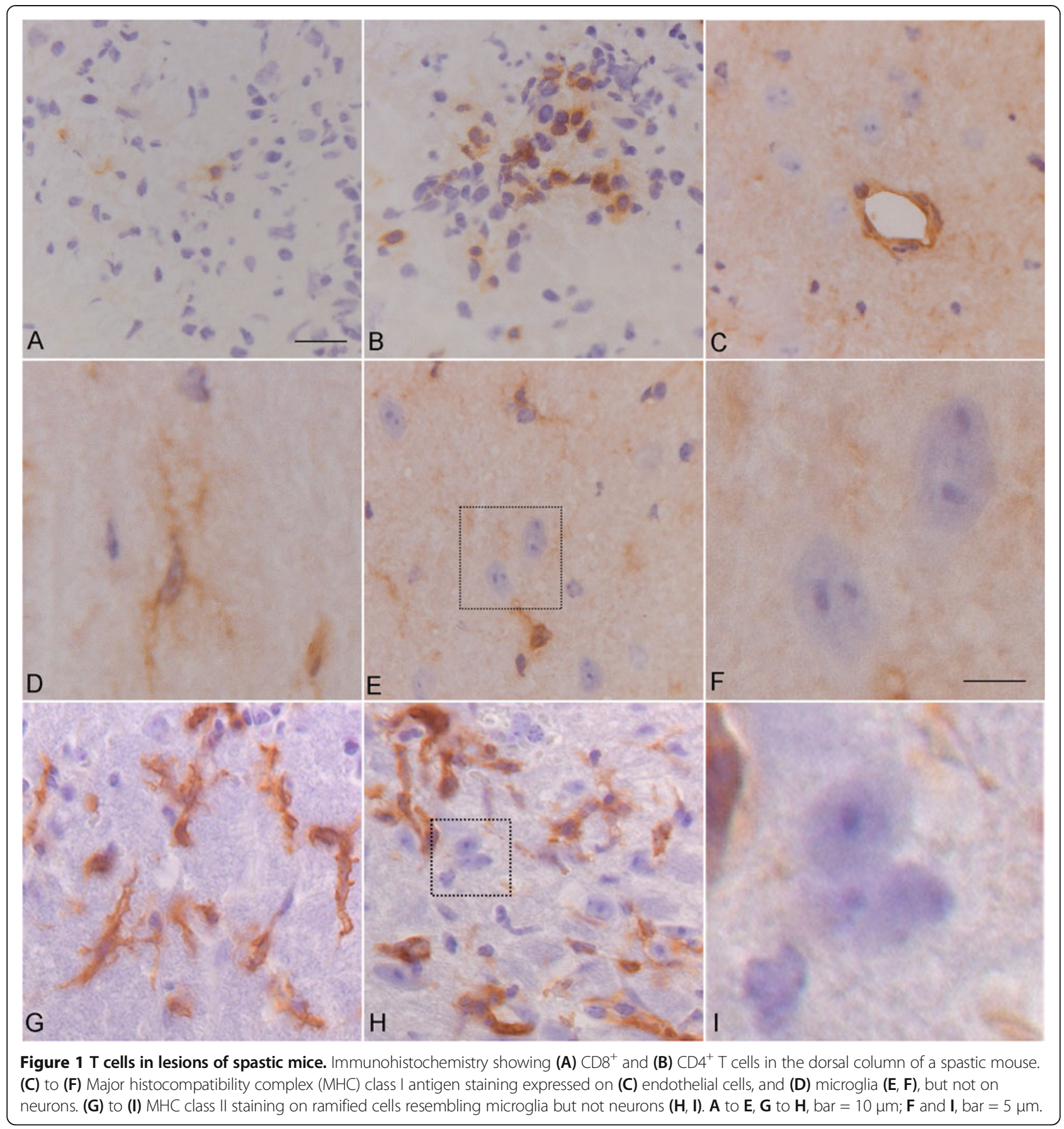

also observed between thickened axons in the lateral funiculus and adjacent to Neu- $\mathrm{N}^{+}$neurons in the spinal cord (Figure 2E, F), these were rare as compared with $\mathrm{CD} 4^{+} \mathrm{T}$ cells.

\section{Cytotoxic molecules are present in the spinal cord of NF-L immunized mice}

To examine the potential mechanisms of T-cell-mediated axonal damage, the expression of the cytotoxic molecules granzyme B and perforin was examined in the spinal cord of spastic mice. Immunostaining revealed the expression of granzyme $\mathrm{B}$ in spinal cord lesions of mice immunized with NF-L (Figure 3A). Immunodetection of perforin in mouse CNS was not possible due to lack of specific mAbs. Instead, RT-PCR on spinal cord tissues was performed and showed that perforin mRNA levels were increased in rmNF-L immunized mice compared with controls (Figure $3 \mathrm{~B}$ ). In addition, granzyme $\mathrm{B}$ and perforin were expressed by peripheral $\mathrm{CD} 4^{+} \mathrm{T}$ cells from NF-L immunized mice compared with $\mathrm{CD}^{+} \mathrm{T}$ cells (data not shown). 


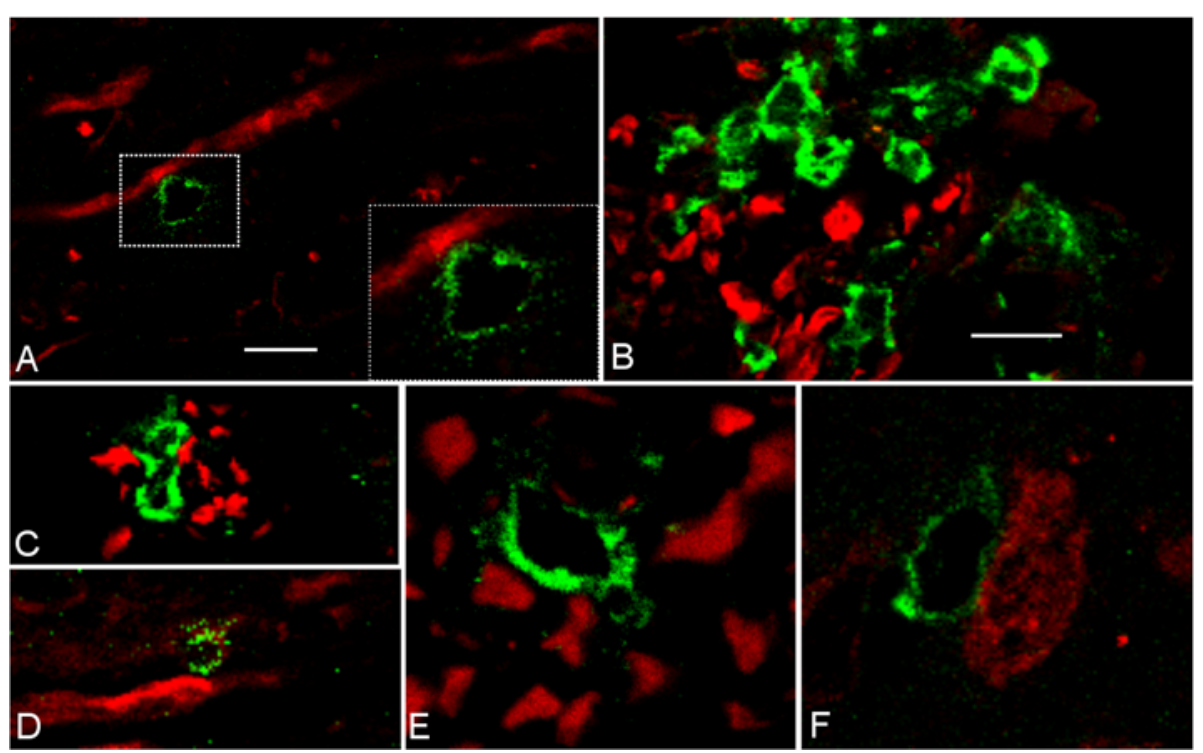

Figure $2 \mathrm{~T}$ cells associated with axonal damage in spastic mice. Confocal images of (A) $\mathrm{CD}^{+} \mathrm{T}$ cell (green) in contact with $\mathrm{SMI} 32^{+}$axon (red). (B, C) CD4 $4^{+} \mathrm{T}$ cells in area of axonal damage and (D) next to swollen NF- $\mathrm{L}^{+}$axons. (E) $C D 8^{+} \mathrm{T}$ cells between NF- $\mathrm{L}^{+}$axons and (F) Neu-N neurons in the spinal cord. $\mathbf{A}, \mathbf{E}, \mathbf{F}$, bar $=5 \mu \mathrm{m} ; \mathbf{B}, \mathbf{C}, \mathbf{D}$, bar $=25 \mu \mathrm{m}$.

\section{Autoimmunity to NF-L exacerbates $\mathrm{MOG}^{35-55}$ experimental} autoimmune encephalomyelitis in $\mathrm{ABH}$ mice

To increase the likelihood of exposing NF-L protein in the $\mathrm{CNS}, \mathrm{ABH}$ mice were co-immunized with $\mathrm{MOG}^{35-55}$ to induce myelin damage (Figure 4). While $\mathrm{SCH}$ induced classical EAE about 11 days after immunization, coimmunization of rmNF-L with $\mathrm{MOG}^{35-55}$ induced significantly augmented disease in which spasticity was observed on days 16 and $17(P=0.005)$, indicating that myelin damage may first be necessary to expose neuronal antigens. Within this timeframe, mice immunized with rmNF-L only did not develop clinical disease as we have reported previously [7]. However, by day 21, NF-L immunized mice did develop neurological signs of disease with a mean day of onset $19.8 \pm 1.6$, EAE score $1.5 \pm 1.0$, group score $0.5 \pm 0.4$ and an EAE incidence of $50 \%$.

\section{Immunodominant B-cell and T-cell epitopes of neurofilament} light in mice

To determine immunodominant epitopes in the NF-L protein, antibody and T-cell responses to synthetic 16-mer overlapping peptides spanning the mouse NF-L sequence (Table 1) were screened in $\mathrm{ABH}$ and SJL/J mice immunized with rmNF-L in CFA [19]. Since we have seen before that immunization with NF-L in Biozzi mice can result in antibody production and binding to axons, it was of interest to screen the antibody responses to the overlapping peptides [7]. Antibody reactivity to NF-L peptides in both strains of mice revealed an immunodominant region that corresponds to the overlapping region (NF-L amino acids 169 to 208) and the single region (amino acids 169 to 184) in $\mathrm{ABH}$ and SJL/J mice respectively (Figure $5 \mathrm{~A}, \mathrm{~B}$ ). This region is located in the coil $1 \mathrm{~b}$ domain of NF-L. In line with our observations, these motifs (amino acids 154 to 195) are likely to be linear B-cell epitopes according to the BCPred prediction algorithm [24]. In SJL/J mice, NF-L specific antibodies also reacted to the single peptides amino acids 41 to 56 and amino acids 345 to 360 (Figure 5B). In both strains, the mean absorbance values for antibody response to rmNF-L protein were within the optical density range of 1.21 to 1.34 .

Immunodominant T-cell responses to two dominant regions, amino acids 241 to 288 and 345 to 368, were observed in $\mathrm{ABH}$ mice (Figure 6A). In comparison, T-cell responses in SJL/J mice were observed to amino acids 241 to 288 (Figure 6B). In both strains, the SIs were lower than responses to rmNF-L alone ( $\mathrm{SI}=5$ to 10$)$. These results are in line with data using overlapping 15-mer peptides of NF-L in $\mathrm{ABH}$ mice (data not shown), indicating that immunodominant epitopes reside within the rod domain (linker 2 and coil 2B) of NF-L. No overlapping peptide induced significant proliferation in cells from CFA immunized mice.

\section{Pathogenicity of immunodominant epitopes}

To determine the pathogenicity of immunodominant epitopes, ABH mice were immunized with individual NF-L peptides spanning the T-cell immunodominant region (amino acids 241 to 272) or with a pool of immunodominant B-cell epitopes. In contrast to $\mathrm{SCH}$-induced 


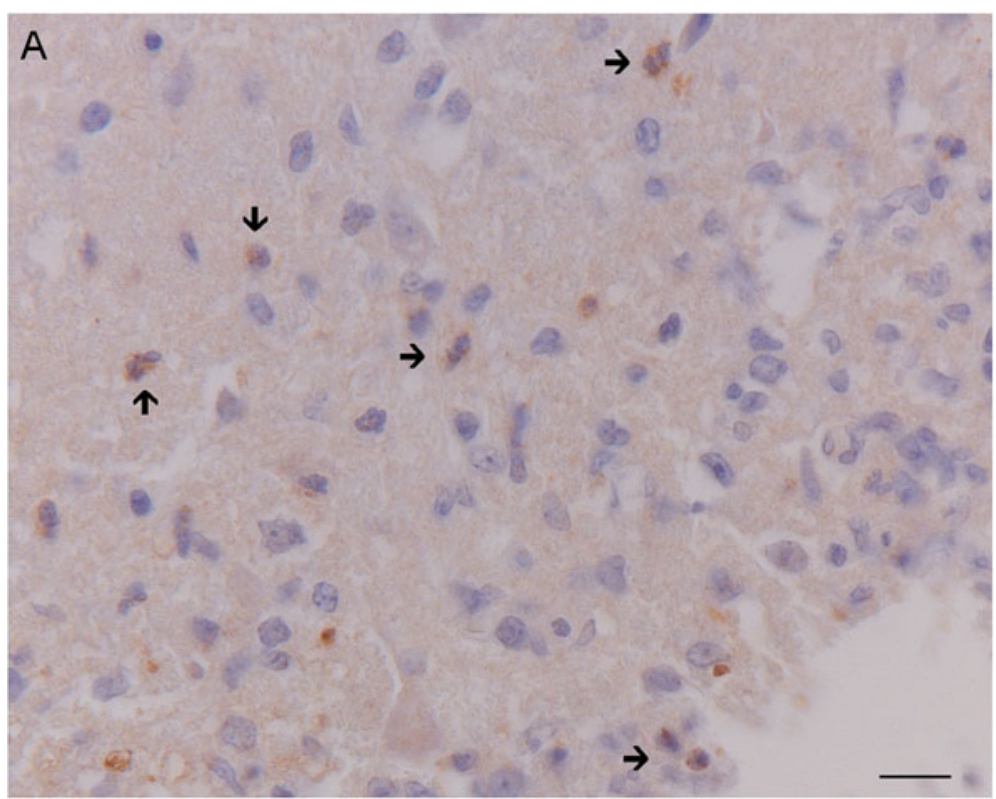

B

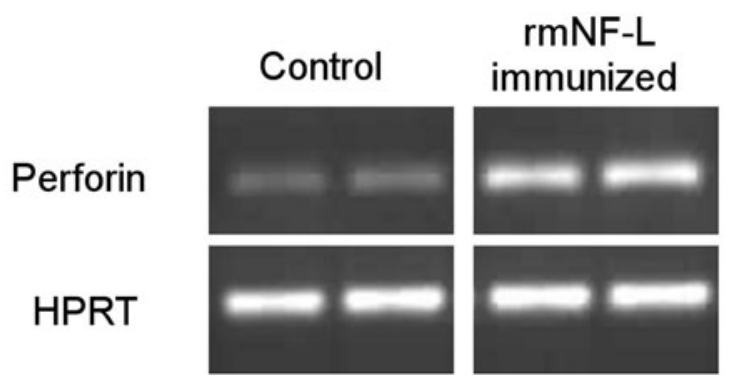

Figure 3 Production of cytotoxic molecules in spastic mice. (A) Granzyme B-positive staining (indicated by arrows) was performed on paraffin-embedded spinal cord sections: bar $=10 \mu \mathrm{m}$. (B) Gel electrophoresis of PCR products show perforin expression is increased in spastic mice (hypoxanthine guanine phosphoribosyl transferase (HPRT) = internal control). NF-L, neurofilament light.

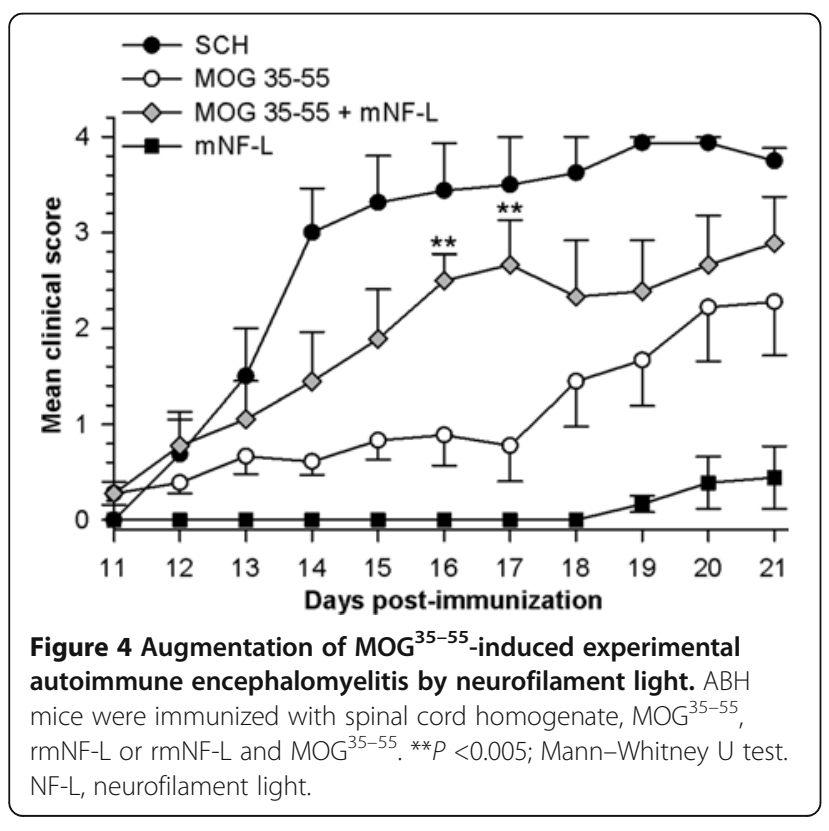

EAE, immunization of ABH mice with amino acids 241 to 256,249 to 264,257 to 272,345 to 360 and 353 to 368 induced spasticity of the tail and hind limbs in line with studies using rmNF-L (Table 2, panel A) [7]. Immunization with NF-L peptides also induced a delayed onset of clinical signs occurring 10 days later than SCH-induced EAE (Table 2, panel A). Rota-rod studies did not reveal additional signs of neurological disease (data not shown). SJL/J mice immunized with rmNF-L also developed very mild clinical disease of spasticity (data not shown). The pathogenic potential of NF-L peptides was also observed with some, but not all, peptides predicted to bind with $\mathrm{H} 2-\mathrm{A}^{\mathrm{g} 7}$ (Table 2, panel $\mathrm{B}$ ). No significant effect was observed after immunization with the immunodominant B-cell epitopes (amino acids 169 to 208) (Additional file 1).

Additionally, the capacity of NF-L-specific $\mathrm{T}$ cells to transfer spasticity was tested in $\mathrm{ABH}$ mice. Lymph node and spleen cells from rmNF-L-immunized $\mathrm{ABH}$ mice were 


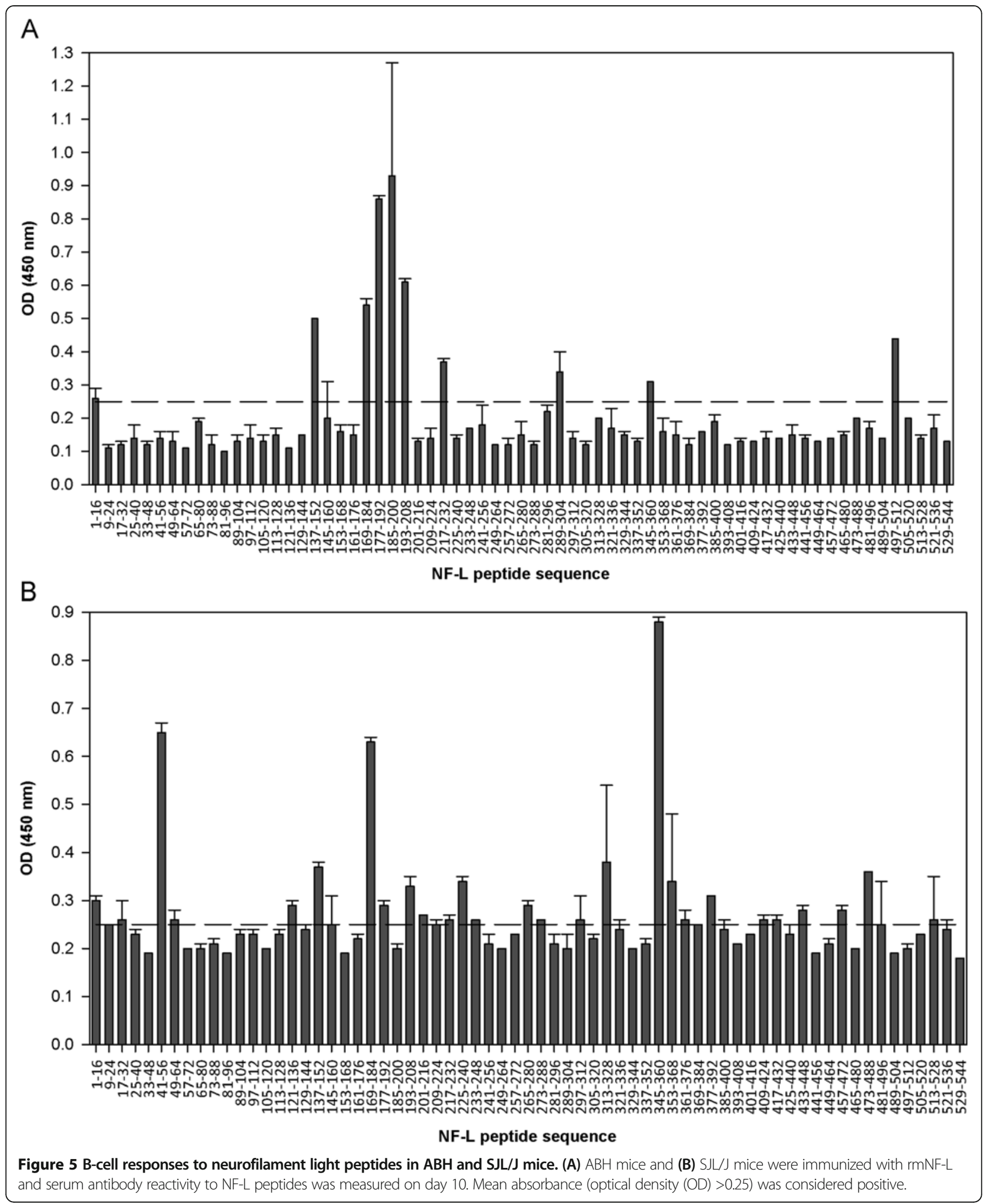

collected 12 days after immunization and stimulated for 10 days in vitro with rmNF-L. Activated cells were adoptively transferred into irradiated naïve recipients and followed until day 25. Mild signs of disease (score 0.5) were observed in two of seven mice revealing the pathogenic potential of T cells to NF-L (data not shown). 


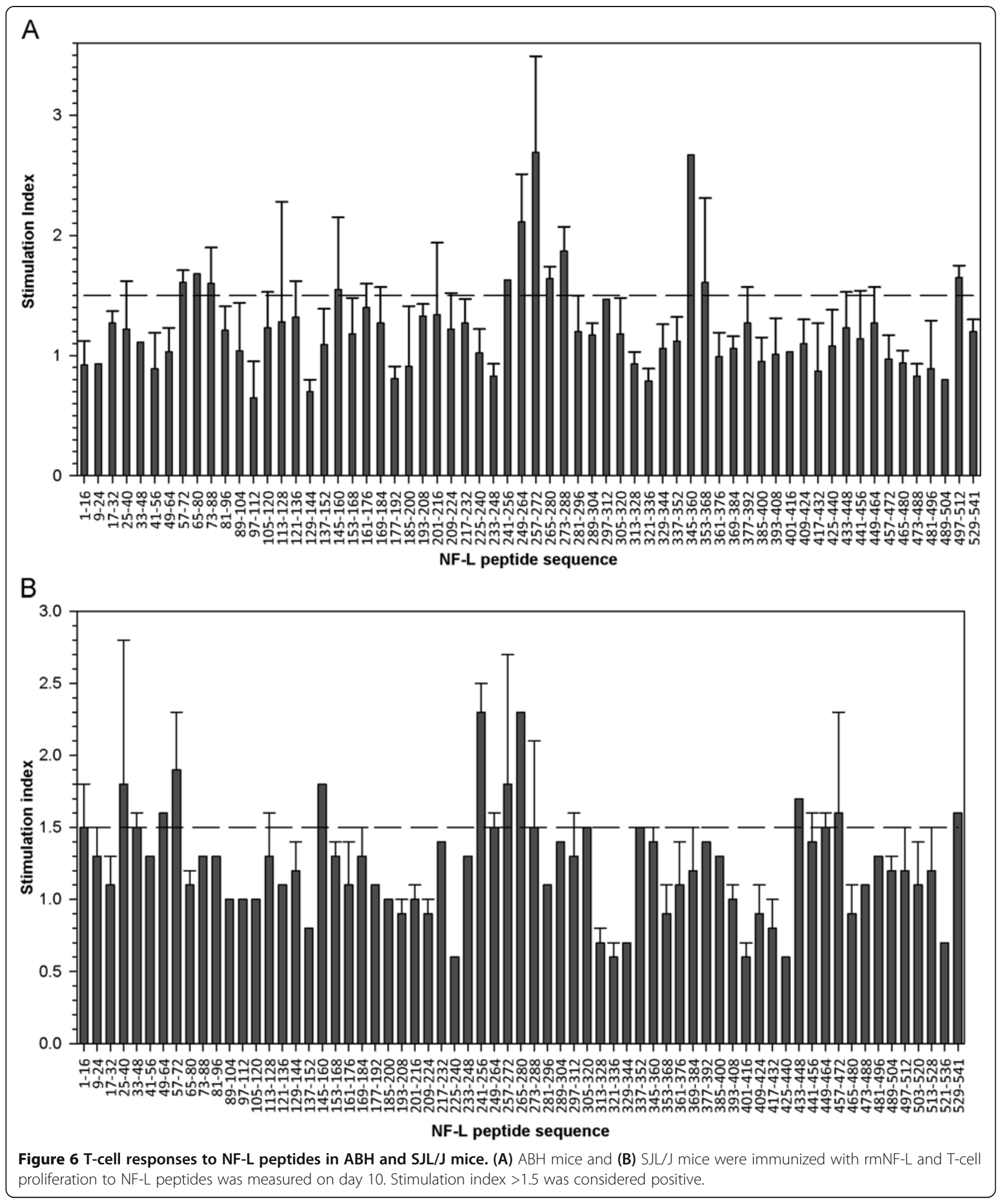

\section{Discussion}

Accumulating evidence indicates that as well as myelinspecific $\mathrm{T}$ cells, neuronal-specific $\mathrm{T}$ cells may gain access to the CNS and contribute to neurodegeneration. Immune responses to neurons are reported in Rasmussen's encephalitis [25], Alzheimer's disease [26], Parkinson's disease [27] and paraneoplastic disorders [5], underscoring the potential role of pathogenic neuronal-reactive $\mathrm{T}$ cells in 
Table 2 Pathogenic neurofilament-light peptides in ABH mice

\begin{tabular}{|c|c|c|c|c|}
\hline Antigen/peptides & Number with EAE & Mean group score ${ }^{b}$ & Mean EAE score $^{c}$ & Mean day of onset \\
\hline \multicolumn{5}{|l|}{ Panel A } \\
\hline $\mathrm{SCH}$ & $4 / 4$ & $4.0 \pm 0.0^{*}$ & $4.0 \pm 0.0$ & $15.3 \pm 0.3$ \\
\hline$r m N F-L$ & $4 / 5$ & $0.7 \pm 0.3^{*}$ & $0.9 \pm 0.2$ & $31.0 \pm 1.4$ \\
\hline 241 to 256 & $1 / 5$ & $0.1 \pm 0.1$ & $0.5 \pm \mathrm{N} / \mathrm{A}$ & $21.0 \pm N / A$ \\
\hline 249 to 264 & $5 / 5$ & $0.9 \pm 0.3^{*}$ & $0.9 \pm 0.3$ & $25.6 \pm 6.4$ \\
\hline 257 to 272 & $3 / 5$ & $0.4 \pm 0.2$ & $0.7 \pm 0.2$ & $29.3 \pm 0.6$ \\
\hline 265 to 280 & $0 / 5$ & N/A & N/A & N/A \\
\hline 273 to 288 & $0 / 5$ & N/A & N/A & N/A \\
\hline 345 to 360 & $3 / 5$ & $0.7 \pm 0.3$ & $1.2 \pm 0.3$ & $29.3 \pm 0.3$ \\
\hline 353 to 368 & $3 / 5$ & $0.5 \pm 0.2$ & $0.8 \pm 0.2$ & $25.7 \pm 4.4$ \\
\hline \multicolumn{5}{|l|}{ Panel B } \\
\hline 129 to 144 & $2 / 5$ & $0.2 \pm 0.1$ & $0.5 \pm 0.0$ & $18.5 \pm 6.5$ \\
\hline 297 to 312 & $2 / 5$ & $0.2 \pm 0.1$ & $0.5 \pm 0.0$ & $30.5 \pm 0.5$ \\
\hline 313 to 328 & $0 / 5$ & N/A & N/A & N/A \\
\hline 113 to 128,281 to 296,289 to 304,321 to 336 (4) & $3 / 4$ & $0.9 \pm 0.4$ & $1.2 \pm 0.3$ & $28.7 \pm 0.7$ \\
\hline 201 to 216,377 to 392,457 to 472 (3) & $0 / 5$ & $\mathrm{~N} / \mathrm{A}$ & N/A & N/A \\
\hline \multicolumn{5}{|l|}{ Panel C } \\
\hline CFA & $0 / 5$ & N/A & N/A & N/A \\
\hline
\end{tabular}

MS in which axonal damage correlates with disability. To examine the role of $\mathrm{T}$ cells in neurodegeneration, we have studied autoimmune-meditated neurodegeneration in mice immunized with NF-L in which spasticity and paralysis, clinical features characteristic of MS, are observed $[7,8]$. In previous studies, infiltration of $\mathrm{CD}^{+}$and $\mathrm{B}_{2} 20^{+}$cells and immunoglobulin deposits were observed in spinal cord lesions of NF-L immunized mice [7].

In this study, we aimed to further investigate the cellular and humoral immune response in the mouse model of NF-L-induced neurodegeneration. Immunohistochemistry revealed the association of both $\mathrm{CD}^{+}$and $\mathrm{CD}^{+} \mathrm{T}$ cells with neuronal damage and the expression of cytotoxic molecules in the CNS. We also identify immunodominant regions and encephalitogenic epitopes on the NF-L protein. Together, our data support the accumulating evidence that $\mathrm{T}$ cells play a role in neuronal and axonal damage in neurodegenerative disorders. Adoptive transfer experiments to test the ability of NF-L peptidespecific $T$ cells to induce disease would be of interest in future studies.

A pre-requisite for antigen-specific $\mathrm{CD}^{+}$cytotoxic damage of neurons is the expression of MHC class I molecules. Strong evidence exists of MHC class I on neurons, neurites and axons, revealing differential expression depending on neuronal subtype, development stage and the inflammatory stimulus. MHC class I expression is highly upregulated on neurons following IFN $\gamma$ treatment but not TNF $\alpha$ [28]. Intriguingly, $\mathrm{CD}^{+} \mathrm{T}$ cells directed to NF-L generated from spastic mice produce high levels of IFN $\gamma$ [4], indicating that $\mathrm{T}$ cells to NF-L could trigger progressive neurodegeneration. Further support for T-cellmediated neuronal damage comes from the finding that, in EAE, myelin-reactive $\mathrm{T}$ cells are activated by neurofilament peptides [29]. Such interaction between T cells and neurons may induce antigen-specific lysis of neurons [30] or dysfunction by impairing electrical signaling [31] and induction of rapid microtubule axonal destabilization [32]. In the spastic model it is unlikely that antigenspecific $\mathrm{CD}^{+} \mathrm{T}$-cell activation leads to neuronal damage since MHC class I was not present on neurons, either in the lesions or in normal appearing tissue. While it is unlikely that $\mathrm{CD}^{+} \mathrm{T}$ cells induce neuronal death in an antigen-specific fashion, as neurons do not express MHC class II, pathogenic $\mathrm{CD}_{4}^{+}$T cells expressing NKG2C could injury neurons and axons expressing HLA-E, as reported for oligodendrocytes in MS [33].

T-cell-mediated neuronal damage may alternatively occur via antigen-independent interactions involving Fas-FasL, TRAIL, CD11a and CD40. In culture, polyclonally activated $\mathrm{CD}^{+}$and $\mathrm{CD}^{+} \mathrm{T}$ cells are cytotoxic to human neurons $[30,32]$, underscoring the potential pathogenic role of both 
$\mathrm{CD}^{+}$and $\mathrm{CD} 8^{+} \mathrm{T}$ cells. In line with these studies, our results show that granzyme $\mathrm{B}$ and perforin are present in the lesions of spastic mice, indicating that neuronal damage is more likely due to antigen-independent mechanisms. The predominance of $\mathrm{CD}^{+}{ }^{+} \mathrm{T}$ cells in the lesions of NF-L immunized mice may be due to selective recruitment or selective depletion of $\mathrm{CD}^{+} \mathrm{T}$ cells [34]. Moreover, the ratio between the T-cell subsets in the lesions in our model is similar to myelin-induced EAE [35]. Further studies on the expression of cytotoxic molecules in T-cell subpopulations in the CNS of NF-L immunized mice will be necessary.

Our observations that co-immunization with MOG and NF-L leads to exacerbated disease is pertinent to what might occur in MS during myelin damage, in which neurons may be more vulnerable to immune responses to neuronal antigens. In this way, the course of neuronal degeneration might be accelerated in the presence of NF-L reactive T cells [4] and antibodies to NF in MS [36].

EAE studies have been instrumental in identifying the role of $\mathrm{T}$ cells and antibodies to myelin in disease. These have revealed important information about peptide:MHC:T-cell receptor interactions crucial for development of tolerance regimes using altered peptide ligands or tolerogenic routes for delivery of pathogenic peptides to modulate myelin-specific $\mathrm{T}$ cells $[37,38]$. These approaches have proved effective in chronic EAE models, preventing the clinical relapses, but do not control progressive disease [37], indicating that mechanisms other than myelin autoimmunity, such as autoimmunity to neuronal proteins, are involved in neurodegeneration in MS.

In ABH mice, immunization with MOG and proteolipid protein readily induces neurological disease in which flaccid paralysis and preferential myelin loss is observed. In contrast, immunization with NF-L protein induces a predominantly spastic disease in which neuronal damage is the primary pathological feature. To determine the pathogenic potential of NF-L peptide, we used a peptide mapping approach and identified a peptide core within the NF-L protein that contains similar elements to previously defined $\mathrm{H} 2-\mathrm{A}^{\mathrm{g} 7}$ motifs within myelin basic protein, MOG and proteolipid protein (Table 3) [19]. This supports many of the predictions made by computer modeling of peptide $\mathrm{H} 2-\mathrm{A}^{\mathrm{g} 7}$ interactions [39]. Similar to the finding following immunization with myelin antigens [19], several encephalitogenic epitopes were identified in NF-L immunized ABH mice. One should note that when using overlapping peptides, inappropriate sequence alignment could mask encephalitogenic epitopes or induce peptide epitopes to become tolerogenic [40]. In addition, neurofilament modulates oligodendrocyte proliferation and differentiation [41], thereby masking the possible pathogenic impact of these proteins. Peptide mapping approaches have identified immunodominant
Table 3 Pathogenic peptides associated with neurological disease in ABH mice

\begin{tabular}{lcl}
\hline $\begin{array}{l}\text { Protein and peptide } \\
\text { residues }\end{array}$ & Amino acid sequence & Reference \\
\hline PLP 54 to 76 & DYEYLINVIHAFQYVIGASF & {$[19]$} \\
MBP 12 to 35 & LATASTMDHARHGFLPRHRDTSGI & {$[19]$} \\
MOG 1 to 23 & GQFRVIGPGYPIRALVGDEQED & {$[19]$} \\
aB crystallin 52 to 61 & FFLRAPSWI & {$[42]$} \\
NF-L 129 to 144 & SEPSRFRALYEQEIRD & This study \\
NF-L 257 to 272 & ALKDIRAQYEKLAAKN & This study
\end{tabular}

MBP myelin basic protein, MOG myelin oligodendrocyte glycoprotein, NF-L neurofilament light, PLP proteolipid protein.

epitopes of myelin basic protein in mice and humans and prompted tolerance strategies to myelin basic proteinspecific $\mathrm{T}$ cells in MS. Current studies are underway to identify T-cell responses to NF-L epitopes in MS patients who respond to the NF-L protein [4]. These studies may reveal whether such responses are present in subtypes of MS or correlate with extent of cognitive changes or progressive disease. Such findings may be key to the development of personal therapeutic approaches using tolerance regimens.

In conclusion, we show that peptide epitopes of NF-L induce neurological disease and that potentially pathogenic $\mathrm{CD}_{4}{ }^{+} \mathrm{T}$ cells dominate the lesions of NF-L immunized mice, a model for immune-mediated neurodegeneration. Our data suggest that, similar to peptide therapies targeting myelin responses [43], immune therapies targeting neuronal-specific T cells could thus be beneficial in reducing neurodegeneration in inflammatory disorders such as MS.

\section{Consent}

Written informed consent was obtained from the patient for the publication of this report and any accompanying images.

\section{Additional file}

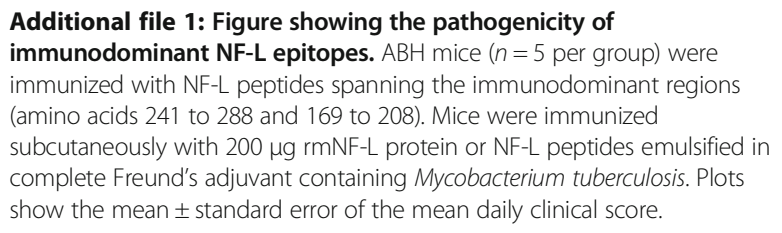

\section{Abbreviations}

BSA: Bovine serum albumin; CNS: Central nervous system; CFA: Complete Freund's adjuvant; EAE: Experimental autoimmune encephalomyelitis; mAb: Monoclonal antibody; MHC: Major histocompatibility complex; MOG: Myelin oligodendrocyte glycoprotein; MS: Multiple sclerosis; NF-L: Neurofilament light; PBS: Phosphatebuffered saline; PCR: Polymerase chain reaction; RT: Reverse transcriptase; SCH: Spinal cord homogenate; Sl: Stimulation index.

\section{Competing interests}

The authors have no competing interests. 


\section{Authors' contributions}

FP, BJvdS, and SA designed research, performed research, analyzed data, and wrote the manuscript. MV, MK, CB, RP-B, KU, GP, WG, RH, AR, PvdV, and DB performed research, analyzed data, and wrote the manuscript. All authors read and approved the final manuscript.

\section{Authors' information}

Prof. David Baker and Prof. Sandra Amor share the senior authorship.

\section{Acknowledgements}

The authors thank Bert van het Hof for technical assistance. This work was supported by Stichting MS Research, The Netherlands, grant number 07-627, the DANA foundation and by the MS Society of Great Britain and Northern Ireland, grant number NSCG-1F7R.

\section{Author details}

${ }^{1}$ Neuroimmunology Unit, Blizard Institute, Bart's and the London School of Medicine and Dentistry, Queen Mary University of London, London E1 2AT, UK. ${ }^{2}$ Pathology Department, VU University Medical Center, Amsterdam, The Netherlands, De Boelelaan 1117, 1081 HV, Amsterdam, The Netherlands. ${ }^{3}$ Institute of Neuroanatomy, Faculty of Medicine, RWTH Aachen University, Aachen 52062, Germany. ${ }^{4}$ Department of Immunology, Erasmus MC, University Medical Center, Rotterdam 3062 PA, The Netherlands. ${ }^{5}$ Molecular Cell Biology and Immunology Department, VU Medical Center, Amsterdam, The Netherlands, De Boelelaan 1117, 1081 HV, Amsterdam, The Netherlands.

Received: 8 July 2013 Accepted: 8 September 2013

Published: 22 September 2013

\section{References}

1. Hauser SL, Bhan AK, Gilles F, Kemp M, Kerr C, Weiner HL: Immunohistochemical analysis of the cellular infiltrate in multiple sclerosis lesions. Ann Neurol 1986, 19:578-587

2. Fletcher JM, Lalor SJ, Sweeney CM, Tubridy N, Mills KH: T cells in multiple sclerosis and experimental autoimmune encephalomyelitis. Clin Exp Immunol 2010, 162:1-11.

3. van Noort JM, Bsibsi M, Gerritsen WH, van der Valk P, Bajramovic JJ, Steinman L, Amor S: Alphab-crystallin is a target for adaptive immune responses and a trigger of innate responses in preactive multiple sclerosis lesions. J Neuropathol Exp Neurol 2010, 69:694-703.

4. Huizinga R, Hintzen RQ, Assink K, van Meurs M, Amor S: T-cell responses to neurofilament light protein are part of the normal immune repertoire. Int Immunol 2009, 21:433-441.

5. Iorio R, Lennon VA: Neural antigen-specific autoimmune disorders. Immunol Rev 2012, 248:104-121.

6. Zhang Y, Da RR, Guo W, Ren HM, Hilgenberg LG, Sobel RA, Tourtellotte WW, Smith MA, Olek M, Gupta S, Robertson RT, Nagra R, Van Den Noort S, Qin Y: Axon reactive $B$ cells clonally expanded in the cerebrospinal fluid of patients with multiple sclerosis. J Clin Immunol 2005, 25:254-264.

7. Huizinga R, Heijmans N, Schubert P, Gschmeissner S, Hart BA T, Herrmann H, Amor S: Immunization with neurofilament light protein induces spastic paresis and axonal degeneration in Biozzi ABH mice. J Neuropathol Exp Neurol 2007, 66:295-304.

8. Huizinga R, Gerritsen W, Heijmans N, Amor S: Axonal loss and gray matter pathology as a direct result of autoimmunity to neurofilaments. Neurobiol Dis 2008, 32:461-470.

9. Beltran E, Hernandez A, Lafuente EM, Coret F, Simo-Castello M, Bosca I, Perez-Miralles FC, Burgal M, Casanova B: Neuronal antigens recognized by cerebrospinal fluid IgM in multiple sclerosis. J Neuroimmunol 2012 247:63-69.

10. Derfuss T, Parikh K, Velhin S, Braun M, Mathey E, Krumbholz M, Kumpfel T, Moldenhauer A, Rader C, Sonderegger P, Pöllmann W, Tiefenthaller C, Bauer J, Lassmann H, Wekerle H, Karagogeos D, Hohlfeld R, Linington C, Meinl E: Contactin-2/TAG-1-directed autoimmunity is identified in multiple sclerosis patients and mediates gray matter pathology in animals. Proc Natl Acad SCi US A 2009, 106:8302-8307.

11. Hoftberger R, Aboul-Enein F, Brueck W, Lucchinetti C, Rodriquez M, Schmidbauer $M$, Jellinger $K$, Lassmann $H$ : Expression of major histocompatibility complex class I molecules on the different cell types in multiple sclerosis lesions. Brain Pathol 2004, 14:43-50
12. Gobel K, Melzer N, Herrmann AM, Schuhmann MK, Bittner S, Ip CW, Hunig T, Meuth SG, Wiendl H: Collateral neuronal apoptosis in CNS gray matter during an oligodendrocyte-directed CD8(+) T cell attack. Glia 2010, 58:469-480.

13. Werner P, Pitt D, Raine CS: Glutamate excitotoxicity - a mechanism for axonal damage and oligodendrocyte death in multiple sclerosis? J Neural Transm Supp/ 2000:375-385.

14. Woodroofe MN: Cytokine production in the central nervous system. Neurology 1995, 45:S6-S10.

15. Witherick J, Wilkins A, Scolding N, Kemp K: Mechanisms of oxidative damage in multiple sclerosis and a cell therapy approach to treatment. Autoimmune Dis 2010, 2011:164608.

16. Magliozzi R, Howell O, Vora A, Serafini B, Nicholas R, Puopolo M, Reynolds R, Aloisi F: Meningeal B-cell follicles in secondary progressive multiple sclerosis associate with early onset of disease and severe cortical pathology. Brain 2007, 130:1089-1104.

17. Huizinga R, van der Star BJ, Kipp M, Jong R, Gerritsen W, Clarner T, Puentes F, Dijkstra CD, van der Valk $P$, Amor S: Phagocytosis of neuronal debris by microglia is associated with neuronal damage in multiple sclerosis. Glia 2012, 60:422-431

18. Al-lzki S, Pryce G, O'Neill JK, Butter C, Giovannoni G, Amor S, Baker D: Practical guide to the mouse induction of relapsing progressive experimental autoimmune encephalomyelitis in the Biozzi ABH. Mult Scler Relat Disord 2012, 1:29-38.

19. Amor S, O'Neill JK, Morris MM, Smith RM, Wraith DC, Groome N, Travers PJ Baker D: Encephalitogenic epitopes of myelin basic protein, proteolipid protein, myelin oligodendrocyte glycoprotein for experimental allergic encephalomyelitis induction in Biozzi $\mathrm{ABH}(\mathrm{H}-2 \mathrm{Ag} 7)$ mice share an amino acid motif. J Immunol 1996, 156:3000-3008.

20. Rankpep. [http://imed.med.ucm.es/Tools/rankpep.html]

21. Image J: [http://rsb.info.nih.gov/ij/index.html]

22. Braun A, Dang J, Johann S, Beyer C, Kipp M: Selective regulation of growth factor expression in cultured cortical astrocytes by neuro-pathological toxins. Neurochem Int 2009, 55:610-618

23. Butter C, O'Neill JK, Baker D, Gschmeissner SE, Turk JL: An immunoelectron microscopical study of the expression of class II major histocompatibility complex during chronic relapsing experimental allergic encephalomyelitis in Biozzi AB/H mice. J Neuroimmunol 1991, 33:37-42.

24. BCPred: [http://ailab.cs.iastate.edu/bcpreds/]

25. Bien CG, Bauer J, Deckwerth TL, Wiendl H, Deckert M, Wiestler OD Schramm J, Elger CE, Lassmann H: Destruction of neurons by cytotoxic T cells: a new pathogenic mechanism in Rasmussen's encephalitis. Ann Neurol 2002, 51:311-318

26. D'Andrea MR: Evidence linking neuronal cell death to autoimmunity in Alzheimer's disease. Brain Res 2003, 982:19-30.

27. Benkler M, Agmon-Levin N, Hassin-Baer S, Cohen OS, Ortega-Hernandez OD, Levy A, Moscavitch SD, Szyper-Kravitz M, Damianovich M, Blank M, Chapman J, Shoenfeld Y: Immunology, autoimmunity, and autoantibodies in Parkinson's disease. Clin Rev Allergy Immunol 2012, 42:164-171.

28. Neumann $\mathrm{H}$, Cavalie A, Jenne DE, Wekerle $\mathrm{H}$ : Induction of MHC class genes in neurons. Science 1995, 269:549-552.

29. Krishnamoorthy G, Saxena A, Mars LT, Domingues HS, Mentele R, Ben-Nun A Lassmann H, Dornmair K, Kurschus FC, Liblau RS, Wekerle H: Myelin-specific T cells also recognize neuronal autoantigen in a transgenic mouse model of multiple sclerosis. Nat Med 2009, 15:626-632.

30. Giuliani F, Goodyer CG, Antel JP, Yong WW: Vulnerability of human neurons to T cell-mediated cytotoxicity. J Immunol 2003, 171:368-379.

31. Meuth SG, Herrmann AM, Simon OJ, Siffrin V, Melzer N, Bittner S, Meuth P, Langer HF, Hallermann S, Boldakowa N, Herz J, Munsch T, Landgraf P, Aktas O, Heckmann M, Lessmann V, Budde T, Kieseier BC, Zipp F, Wiendl H: Cytotoxic CD8+ T cell-neuron interactions: perforin-dependent electrical silencing precedes but is not causally linked to neuronal cell death. J Neurosci 2009, 29:15397-15409.

32. Miller N, Shriver LP, Bodiga VL, Ray A, Basu S, Ahuja R, Jana A, Pahan K, Dittel BN: Lymphocytes with cytotoxic activity induce rapid microtubule axonal destabilization independently and before signs of neuronal death. ASN Neuro 2013, 5:e00105.

33. Zaguia F, Saikali P, Ludwin S, Newcombe J, Beauseigle D, McCrea E, Duquette P, Prat A, Antel JP, Arbour N: Cytotoxic NKG2C + CD4 T cells target oligodendrocytes in multiple sclerosis. J Immuno/ 2013, 190:2510-2518.

34. Zangi L, Zlotnikov Klionsky Y, Yarimi L, Bachar-Lustig E, Eidelstein Y, Shezen E, Hagin D, Ito Y, Takai T, Reich-Zeliger S, Lask A, Milstein O, Jung S, Shinder V, 
Reisner Y: Deletion of cognate CD8 T cells by immature dendritic cells: a novel role for perforin, granzyme A, TREM-1, and TLR7. Blood 2012, 120:1647-1657.

35. Allen SJ, Baker D, O'Neill JK, Davison AN, Turk JL: Isolation and characterization of cells infiltrating the spinal cord during the course of chronic relapsing experimental allergic encephalomyelitis in the Biozzi AB/H mouse. Cell Immunol 1993, 146:335-350.

36. Silber E, Semra YK, Gregson NA, Sharief MK: Patients with progressive multiple sclerosis have elevated antibodies to neurofilament subunit. Neurology 2002, 58:1372-1381.

37. Pryce G, O'Neill JK, Croxford JL, Amor S, Hankey DJ, East E, Giovannoni G, Baker D: Autoimmune tolerance eliminates relapses but fails to halt progression in a model of multiple sclerosis. J Neuroimmunol 2005, 165:41-52.

38. Smith PA, Morris-Downes M, Heijmans N, Pryce G, Arter E, O'Neill JK, Hart TB, Baker D, Amor S: Epitope spread is not critical for the relapse and progression of MOG 8-21 induced EAE in Biozzi ABH mice. J Neuroimmunol 2005, 164:76-84.

39. Liu GY, Baker D, Fairchild S, Figueroa F, Quartey-Papafio R, Tone M, Healey D, Cooke A, Turk JL, Wraith DC: Complete characterization of the expressed immune response genes in Biozzi $\mathrm{AB} / \mathrm{H}$ mice: structural and functional identity between AB/H and NOD A region molecules. Immunogenetics 1993, 37:296-300.

40. Miller A, Al-Sabbagh A, Santos LM, Das MP, Weiner HL: Epitopes of myelin basic protein that trigger TGF-beta release after oral tolerization are distinct from encephalitogenic epitopes and mediate epitope-driven bystander suppression. J Immunol 1993, 151:7307-7315.

41. Fressinaud C, Eyer J: Axoskeletal proteins prevent oligodendrocyte from toxic injury by upregulating survival, proliferation, and differentiation in vitro. Neurochem Int 2012, 62:306-313.

42. Thoua NM, van Noort JM, Baker D, Bose A, van Sechel AC, van Stipdonk MJ, Travers PJ, Amor S: Encephalitogenic and immunogenic potential of the stress protein alphaB-crystallin in Biozzi ABH (H-2A(g7)) mice. J Neuroimmunol 2000, 104:47-57.

43. Bar-Or A, Vollmer T, Antel J, Arnold DL, Bodner CA, Campagnolo D, Gianettoni J, Jalili F, Kachuck N, Lapierre Y, Niino M, Oger J, Price M, Rhodes S, Robinson WH, Shi FD, Utz PJ, Valone F, Weiner L, Steinman L, Garren H: Induction of antigen-specific tolerance in multiple sclerosis after immunization with DNA encoding myelin basic protein in a randomized, placebo-controlled phase 1/2 trial. Arch Neurol 2007, 64:1407-1415.

doi:10.1186/1742-2094-10-118

Cite this article as: Puentes et al:: Characterization of immune response to neurofilament light in experimental autoimmune encephalomyelitis. Journal of Neuroinflammation 2013 10:118.

\section{Submit your next manuscript to BioMed Central and take full advantage of:}

- Convenient online submission

- Thorough peer review

- No space constraints or color figure charges

- Immediate publication on acceptance

- Inclusion in PubMed, CAS, Scopus and Google Scholar

- Research which is freely available for redistribution 